\title{
Implementation of a School Physical Activity Policy Improves Student Physical Activity Levels: Outcomes of a Cluster-Randomized Controlled Trial
}

\author{
Nicole K. Nathan, Rachel L. Sutherland, Kirsty Hope, Nicole J. McCarthy, Matthew Pettett, \\ Ben Elton, Rebecca Jackson, Stewart G. Trost, Christophe Lecathelinais, Kathryn Reilly, \\ John H. Wiggers, Alix Hall, Karen Gillham, Vanessa Herrmann, and Luke Wolfenden
}

\begin{abstract}
Aim: To assess the impact of a multistrategy intervention designed to improve teachers' implementation of a school physical activity (PA) policy on student PA levels. Methods: A cluster-randomized controlled trial was conducted in 12 elementary schools. Policy implementation required schools to deliver 150 minutes of organized PA for students each week via physical education, sport, or class-based activities such as energizers. Schools received implementation support designed using the theoretical domains framework to help them implement the current policy. Results: A total of 1,502 children in kindergarten to grade 6 participated. At follow-up compared with control, students attending intervention schools had, measured via accelerometer, significantly greater increases in school day counts per minute $(97.5 ; 95 \%$ confidence interval [CI], 64.5 to 130.4 ; $P<.001)$ and moderate to vigorous physical activity (MVPA) $(3.0 ; 95 \% \mathrm{CI}, 2.2-3.8, P<.001)$ and a greater decrease in sedentary time $(-2.1 ; 95 \% \mathrm{CI},-3.9$ to $-0.4, P=.02)$ per school day. Teachers in intervention schools delivered significantly more minutes (36.6 min) of PA to their students at follow-up (95\% CI, 2.7-70.5, $P=.04$ ). Conclusions: Supporting teachers to implement a PA policy improves student PA. Additional strategies may be needed to support teachers to implement activities that result in larger gains in student MVPA.
\end{abstract}

Keywords: teaching, physical education, implementation science, theoretical domains framework, elementary students, energizers

For children aged 5-12 years, participation in at least 60 minutes of daily physical activity (PA) is important for their healthy growth and development ${ }^{1}$ as well as protection against future chronic diseases. ${ }^{2}$ Despite this, international research indicates that the majority of children are not sufficiently active. ${ }^{3}$ Creating environments that are supportive of children's PA has been identified as a public health priority. ${ }^{2}$

As schools provide almost universal access to children from all socioeconomic and cultural backgrounds, ${ }^{4}$ they have been recommended as a key setting for the delivery of population-wide PA initiatives. Systematic reviews have found that interventions that increase opportunities to be physically active during the school day through regular quality physical education (PE), sport, or PA in the classroom, such as energizers, are effective in increasing children's moderate to vigorous physical activity (MVPA). ${ }^{1,5,6}$ Consequently, as part of its Global Strategy on Diet, Physical Activity and Health, ${ }^{2}$

Nathan, Sutherland, McCarthy, Pettett, Elton, Jackson, Lecathelinais, Reilly, Wiggers, Gillham, Herrmann, and Wolfenden are with Hunter New England Population Health, Hunter New England Area Health Service, Newcastle, Wallsend, NSW, Australia. Nathan, Sutherland, Hope, and Wolfenden are with the School of Medicine and Public Health, The University of Newcastle, Callaghan, NSW, Australia. Nathan, Sutherland, Wiggers, Hall, and Wolfenden are also with the Priority Research Centre for Health Behaviour, The University of Newcastle, Callaghan, NSW, Australia. Nathan, Sutherland, McCarthy, Pettett, Elton, Jackson, Lecathelinais, Reilly, Wiggers, Hall, Herrmann, and Wolfenden are with the Hunter Medical Research Institute, New Lambton Heights, NSW, Australia. Trost is with the Institute of Health and Biomedical Innovation, Centre for Children's Health Research, Queensland University of Technology, Brisbane, Queensland, Australia. Nathan (Nicole.Nathan@ health.nsw.gov.au) is corresponding author. the World Health Organization recommended the development and implementation of school policies that promote PA. Governments internationally have responded to such recommendations by developing guidelines or policies mandating a minimum accumulated time or intensity that schools are to schedule as structured PA for children. ${ }^{7-10}$ For example, in parts of the United States and United Kingdom, schools are mandated to schedule up to 120 minutes of PE per week, ${ }^{9-11}$ whereas in parts of Canada schools are required to schedule daily PA, which could be accumulated through PE or other classroom activities, such as energizers. ${ }^{8}$ In New South Wales, Australia, the current policy requires teachers of kindergarten to grade 10 students to schedule a minimum of 150 minutes of moderate, with some vigorous, PA across the school week. ${ }^{7}$

Despite the benefits of implementing such policies, internationally, their population-wide implementation is uncommon. ${ }^{10-13}$ For example, a 2011 study of Canadian elementary school teachers found that only $43 \%$ were implementing the mandatory daily 30 minute PA policy requiring schools to provide organized in-class opportunities for children to be active. ${ }^{8}$ Although implementation of the state-wide mandatory PA policy was met by middle and high school teachers in a mixed methods study of elementary, middle, and high school teachers from San Francisco, the criterion of 100 minutes of PE per week for elementary students was recorded in only $20 \%$ of teachers' schedules and occurred in only one of 20 school observations. ${ }^{11}$ With such poor policy implementation, the potential impact that these policies may have on children's activity levels, if implemented, is largely unknown. The effects of specific organized school PA opportunities, such as in-class activity breaks ("energizers"), have been found to be effective in improving student PA and other cognitive outcomes. ${ }^{5,14,15}$ To our knowledge, the impact that 
improving the implementation of school PA policies requiring minimum time for PA has on student PA levels has not been widely examined in randomized controlled trials. ${ }^{4}$ Given the existence of such policies across multiple jurisdictions internationally, the lack of rigorous evaluation of their impact is an important evidence gap.

Furthermore, there remains very little evidence regarding how best to support the implementation of school-based PA polices and interventions. For example, a recently published Cochrane review ${ }^{4}$ identified only one trial in elementary schools that explicitly aimed to increase the implementation of a mandated school PA policy. This randomized trial, ${ }^{16}$ undertaken in 7 US schools, aimed to compare the quantity and quality of PE lessons conducted by classroom teachers who received intensive training with those conducted by specialist PE teachers and a control. Based on observational data of PE lessons, the study reported a significant improvement in implementation of PA compared with control schools. However, implementation was not sustained once the intensive support was removed. As poor implementation of school PA policies is a fundamental impediment to achieving meaningful improvements in child PA for school-based programs, gathering evidence regarding the effects of support strategies that may improve implementation is urgently required. In the context of these limitations, the primary aim of this pilot study was to assess the effectiveness of an intervention designed to support teachers' implementation of a PA policy on students' activity levels at school.

\section{Methods}

\section{Context}

In 2015, the New South Wales Department of Education in Australia amended its Sport and Physical Activity Policy (here after "policy"), requiring teachers to implement for students in kindergarten to grade 10 a minimum of 150 minutes (up from $120 \mathrm{~min}$ ) of planned moderate, with some vigorous, PA across the school week. ${ }^{7}$ Within most Australian elementary schools, the planning and delivery of PA is the responsibility of generalist classroom teachers. Teachers are able to meet the 150 minutes of planned activity by engagement of students in any combination of PE, sport, or class-based activities such as energizers ${ }^{5}$ or active lessons, ${ }^{17}$ provided they are inclusive of all children and are part of their regular classroom schedule (ie, they cannot include recess and lunch time activities). In addition to each teacher implementing 150 minutes of weekly PA, schools are also required to develop a local school policy that states their commitment to the ongoing implementation of the 150-minute policy. At the time of this study, the 150-minute policy was not yet mandated within Catholic (nongovernment) schools in the study region.
However, the Catholic school system strongly encouraged schools to adopt this policy.

\section{Design and Setting}

This was a pilot of the Physically Active Children in Education intervention. It was conducted as part of a broader $2 \times 2$ factorial cluster randomized controlled trial (RCT), which tested the impact and implementation approach of 2 initiatives: (1) PA support, which was designed to support schools to increase the time scheduled for students to engage in MVPA across the school day and (2) lunchbox support, which was designed to support parents to improve the nutritional quality of student lunchboxes (the results of which are reported elsewhere). ${ }^{18}$ Specifically, 12 Catholic elementary schools in the Hunter region of New South Wales, Australia were randomized to one of 4 treatment groups: (1) PA support only, (2) lunchbox support only, (3) both 1 and 2, or (4) waitlist comparison (see Figure 1). The factorial design provided an efficient opportunity for the health service funder to test the impacts of 2 interventions. Although both PA and nutrition measures were co-primary outcomes, they tested independent interventions, and, thus, a conservative approach to evaluation was applied whereby a lack of an interaction effect between the 2 intervention strategies was assumed. In this article, we aimed to assess the effect of the PA support only (and its implementation) by comparing the PA outcomes of students from schools that received the PA support (groups 1 and 3 ) to those who did not (groups 2 and 4). Ethics approval was obtained from Hunter New England Human Research Ethics Committee (06/07/26/4.04), University of Newcastle (H-2008-0343), and Maitland-Newcastle Catholic Schools Office. The study was prospectively registered with Australian New Zealand Clinical Trials Register ACTRN12616001228471 and follows the Consolidated Standards of Reporting Trials (CONSORT) guidelines for pilot studies (Figure 2).

\section{Participants, Recruitment, and Randomization}

Schools. Catholic schools from the study region were stratified by school size (small or large) and placed in a random order and invited to participate. Schools were excluded if they: were participating in another PA intervention; catered for both elementary and secondary students; were exclusively for children requiring specialist care; or did not use the school communications application ("Skoolbag"), as this was required for the lunchbox treatment group. School principals provided written informed consent. Recruitment continued until 12 schools consented to participate. Following baseline data collection, schools were randomly allocated in a 1:1:1:1 ratio to one of the 4 arms by an independent investigator using a computerized random number generator. Data collectors were blinded to group allocation at baseline and

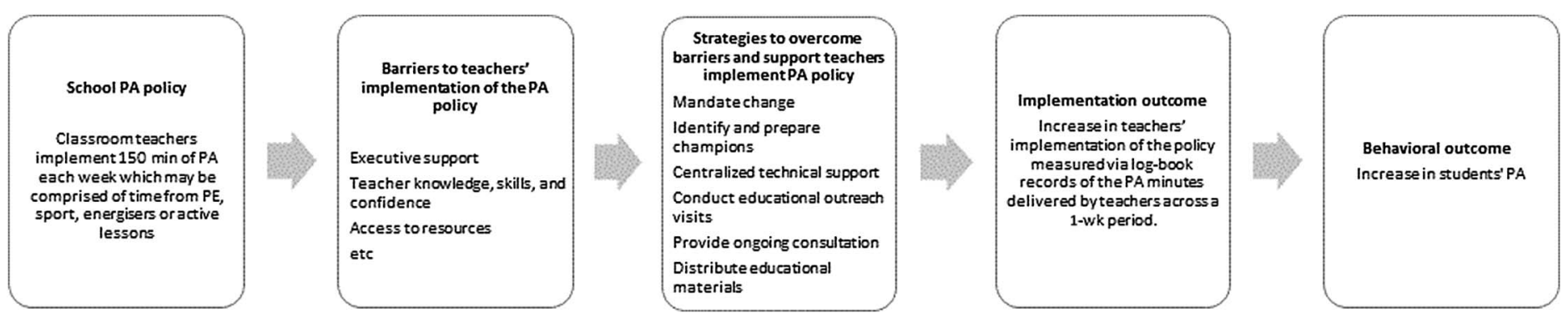

Figure 1 - Logic model detailing the implementation intervention. PA indicates physical activity; PE, physical education. 


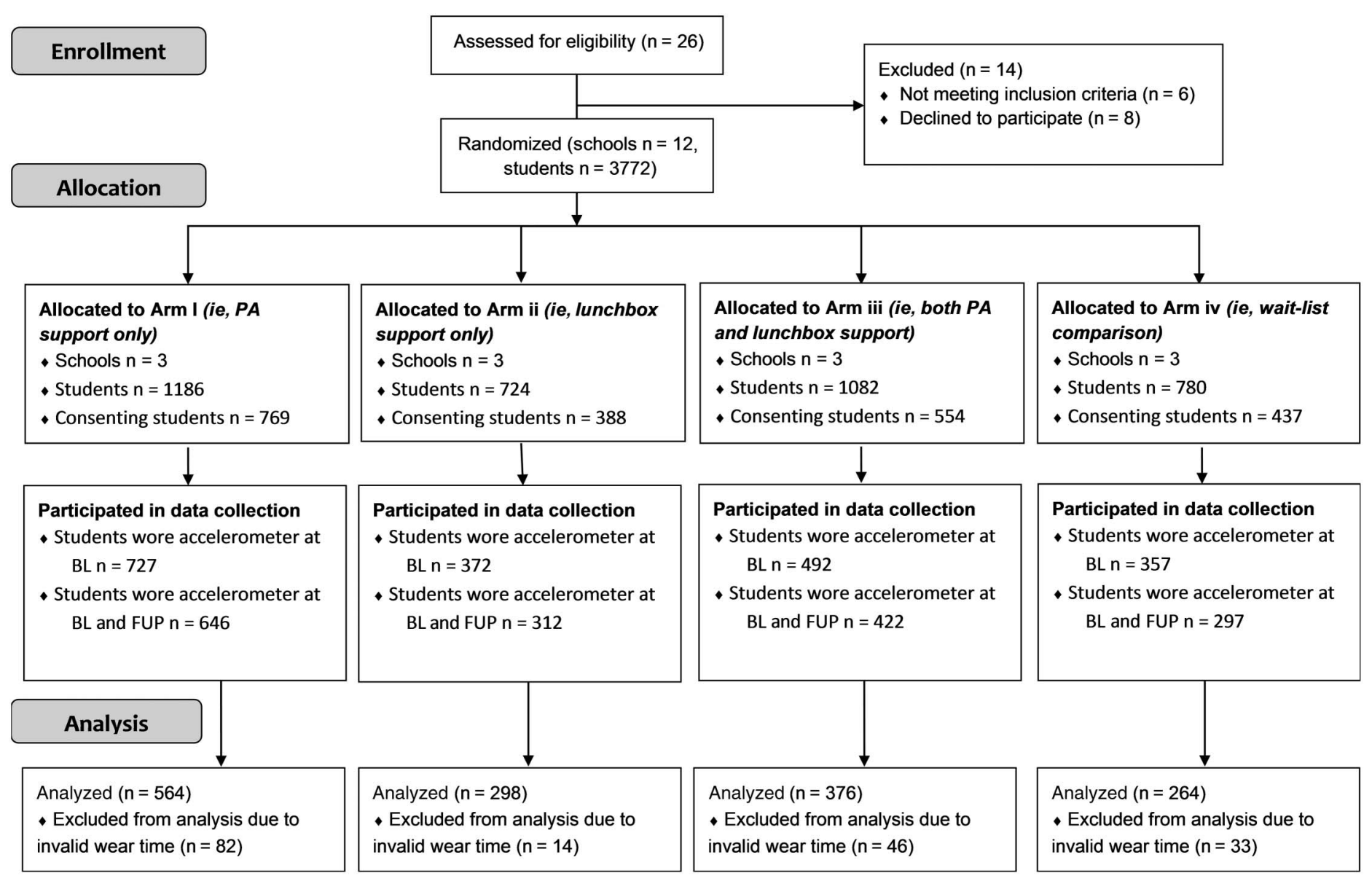

Figure 2 - CONSORT flow chart describing process of participants through the study. PA indicates physical activity, BL, baseline; FUP, Follow-up.

follow-up. However, due to the nature of the intervention, it is possible that data collectors become aware of group allocation at follow-up. School staff were aware of their group allocation.

Students. All students (ages 5-12) attending participating schools were invited to participate in the data collection component of the trial, which required active parent and child consent.

Teachers. Following principal consent, teachers were provided with study information and invited to complete a paper logbook during the week of their school's scheduled data collection visit.

Patient and Public Involvement. Extensive formative research, which included interviews with school teachers and observations of their classroom practices, was undertaken in the development of the intervention. An advisory group consisting of implementation and health behavior scientists, PA experts, and teachers oversaw the trial. At the completion of the trial, participating schools were provided a deidentified summary of trial results.

\section{Implementation Strategy}

The Physically Active Children in Education pilot was designed to increase elementary school teachers' implementation of the PA policy (ie, $150 \mathrm{~min}$ of planned PA across the school week), as recommended by the state government. To support teachers to implement the PA policy, a multistrategy implementation intervention was designed using the theoretical domains framework. ${ }^{19}$
Strategies were purposefully selected to address known barriers to policy implementation, ${ }^{13}$ including barriers reported by school staff that impacted on planning and delivering the main recommended components of PA set out by the policy (PE, sport, other structured and in-class activities). The selected strategies had previously been utilized, were considered acceptable, and were successful in changing the health-promoting policies and practices of schools ${ }^{20,21}$ and other organizations. ${ }^{22}$ See Figure 1 for the broad process logic of the implementation intervention.

Delivered over a 9-month period (January 2017-September 2017), the implementation strategy is described in Table 1 using the Expert Recommendations for Implementing Change taxonomy. ${ }^{23}$

Comparison Schools. Comparison schools were asked to continue their usual PA practices. However, during the trial period, teachers from either intervention or comparison group schools were able to access New South Wales government-run programs directed at supporting school promotion of healthy eating and PA, generally. ${ }^{24}$

Data Collection and Measures. Students' baseline data were collected between February and March 2017. Follow-up data collection occurred approximately 9 months postbaseline (OctoberNovember 2017). Teacher surveys were conducted at follow-up only.

Student and Teacher Demographics. On the student consent form, parents were asked to report their child's sex, age (in years), 
Table 1 Brief Description of the Implementation Strategies

Implementation
strategy

Mandate change

Identify and prepare champions

Develop and distribute educational materials

Conduct educational outreach visits

Provide ongoing consultation

Centralized technical support

\section{Strategy detail}

Support officers met with principals and school executive to communicate the importance and benefits of scheduled PA. Principals and the executive were asked to demonstrate support for implementing the policy through development of a local school PA policy and communicating (eg, via newsletters, assemblies, and staff meetings) expectations of the policy to staff regarding changes to programming of PE, sport, and other activities.

Each school nominated at least 2 in-school champions (existing teachers at the school) who, under the guidance of the principal and with the help of support officers, were responsible for leading their school's implementation of the PA policy. To prepare in-school champions, they attended a 1-d (5 h) face-to-face workshop delivered by support officers, which covered: education about the policy, how to implement $150 \mathrm{~min}$ of organized activities consistent with the policy across the school week, instruction and demonstration of physical activity energizers and PE lessons, and time to begin action planning, which will require in-school champions to identify barriers/facilitators to implementation and possible solutions to overcome these. The training had been accredited by the state educational authority and provided time toward their continuing professional development hours. Schools were offered teacher relief funding to cover in-school champions' attendance at the workshop.

In-school champions received an "intervention manual" and classroom teachers received various printed and electronic instructional materials to assist their scheduling and implementation of PA across the school week. Teachers were provided with examples of school and classroom plans that show teachers how to implement $150 \mathrm{~min}$ of organized activities consistent with the policy across the school week.

Support officers met with all teachers once (face-to-face) as a group in each school for 1-2 $\mathrm{h}$ to introduce the in-school champion and their role in implementing the intervention and as a point of support in the school; to provide instruction on the development of how to implement $150 \mathrm{~min}$ of organized activities consistent with the policy across the school week and demonstrate activities that teachers could use to meet the 150-min policy, including energizers and integrated lessons; and to help answer any questions/ barriers to implementation.

Support officers provided in-school champions with support remotely, that is, via telephone or e-mail twice per term to support implementing the intervention. The focus of these contacts was to help school champions brainstorm solutions to barriers as they arose, continue to support staff to implement $150 \mathrm{~min}$ of organized activities consistent with the policy across the school week, review progress of the schools' implementation plan, and if necessary modification and resetting of goals.

Support officers (a PE teacher and health promotion practitioner) provided technical assistance to schools throughout the study period to support policy implementation by working directly with school champions to overcome barriers and provide expertise support and resources.
Barrier/facilitator addressed (TDF domain)

Perceived school priority (goal) and support from school executive (social influence)

Knowledge of policy (knowledge), competing curriculum priorities (goals), skills to implement the policy (skills), and availability of time to schedule (ECR)

Availability of equipment/time (ECR)

Knowledge of policy (knowledge), competing curriculum priorities (goals), and ease of scheduling (beliefs about capabilities)

Skills to implement the policy (skills) and perceived school priority (goal)

Specialist support (ECR)

Abbreviations: ECR, environmental context and resources; PA, physical activity; PE, physical education; TDF, theoretical domains framework.

and postcode. Teachers were asked to report, via a paper-based survey, their sex, age (in years), years of teaching experience, grade level taught, and whether they were a specialist PE teacher.

Primary Outcome: Students' Mean Daily Activity Counts per Minute. The primary outcome was students' school-day PA, operationalized as the mean activity counts per minute (cpm). All PA outcomes were recorded by an ActiGraph GT3X+ accelerometer (ActiGraph Corporation, Pensacola, FL). Students wore accelerometers Monday through Friday for the whole school day (ie, 9 AM to 3 PM), except for water-based activities. Two research assistants visited each class and demonstrated to students and teachers how to fit the accelerometer to the wrist of their nondominant hand. Teachers distributed and collected the accelerometers each day. Children who did not wear accelerometers for at least $80 \%$ of the school day on at least 3 school days were excluded from analysis. Accelerometer nonwear time was calculated by summing the number of consecutive zero counts accumulated in strings $\geq 20$ minutes. Wear time was estimated by subtracting nonwear time from the total monitoring time for the school day. For each valid school day, cpm was calculated by dividing the total accelerometer counts by the minutes of wear time.

Secondary Outcome: Student Mean Daily Minutes of MVPA and Sedentary Time. Mean daily minutes spent in MVPA (not prospectively registered a priori in ANZCTR) and sedentary time 
during the school day were derived from accelerometer data collected at baseline and follow-up. Accelerometer counts were classified as sedentary, light-intensity PA, and MVPA using the vertical axis wrist cut points developed by Chandler et al. ${ }^{25}$

Secondary Outcome: Teachers' Implementation of the PA Policy Across One School Week. As a measure of improvement in teachers' implementation of the 150-minute policy, the mean minutes that teachers implemented PA (not prospectively registered a priori in ANZCTR) was measured via teacher logbook at follow-up only. For the same school week that children wore accelerometers, at the end of each day teachers completed a paper-based logbook. Specifically, teachers recorded the time that they engaged in all teaching activities across all subjects each day, including what, when, and how long PA was provided. The daily minutes of PA implemented were then summed for each teacher to obtain the total number of minutes of PA that were delivered across that school week. The use of teacher logbooks is frequently used in classroom-based obesity prevention interventions, ${ }^{26,27}$ with high response rates (ie, $\left.>80 \%\right)^{26}$ and established reliability and validity. ${ }^{28}$

\section{Sample Size and Power}

As this was a pilot study, the sample size was based on the number of schools that could be feasibly recruited within the resources and restraints of the study. Based on the feasible sample size of 12 schools (6 per PA arm) with an estimated average of 150 students participating per school, this study had $80 \%$ power to detect an $84.11 \mathrm{cpm}$ between group difference and, assuming the following values that are based on previous research conducted by the investigators, ${ }^{29}$ an SD of 200, an ICC value of .05, and an alpha level of .05.

\section{Analyses}

All analyses were performed in SAS 9.3 (SAS Institute Inc, Cary, NC) in 2018. Descriptive statistics were used to describe the sample of students and teachers with classes dichotomized into lower elementary (kindergarten to grade 2) and upper elementary (grade 3 to grade 6). Students who resided in postcodes ranked in the top $50 \%$ of state postcodes based on the 2016 SocioEconomic Index of Relative Socioeconomic Disadvantage ${ }^{30}$ were categorized as "higher socioeconomic areas," whereas those in the lower 50\% were categorized as "lower socioeconomic areas." Students' postcodes were used to categorize their locality as either "rural" (outer regional, remote, and very remote areas) or "urban" (inner regional or major cities) based upon the 2016 Accessibility/Remoteness Index of Australia. Analyses of study outcomes were performed under an intention to treat (ITT) framework with participants (students and teachers) analyzed according to the group their school was randomized to. As the study was not powered to assess an interaction between the 2 intervention strategies, lunch box and PA (and a significant interaction was not found), a conservative approach was undertaken with the main effects for each intervention analyzed separately (merging the 2 PA groups for analysis).

Statistical analysis of both the primary and secondary outcomes was conducted with linear mixed models. For the student PA outcomes, the between-group differences in the change in students mean levels of PA from baseline to follow-up were assessed. In the PA models, a group-by-time interaction was included as a fixed effect, as was the lunchbox intervention. As there was imbalance between student baseline socioeconomic location and remoteness classification between the experimental groups, these variables were also controlled for by including them as fixed effects in all PA outcome models. Two random intercepts were included in the model, one for school to account for the clustered design of the trial, and one for child (nested within schools) to account for the repeated measurements taken on children. Student PA data were analyzed across the whole school day; however, as the policy requires teachers' implementation of PA during class time, in-class PA exploratory analysis was undertaken to identify the impact on PA during class time. This was calculated by subtracting students' PA time during recess and lunch from their whole school day PA. The primary analyses were performed using all available valid data. As linear mixed models include all available data in the analysis (even those with missing follow-up), this type of analysis aligns with the ITT principle. A sensitivity analysis for the student PA outcomes was conducted using multiple imputation procedures for missing data at follow-up, ${ }^{31}$ with the following variables included in the imputation model: school, time, intervention, and grade. To determine the effects by sex, analysis to assess within sex effects (introducing a 3-way interaction group by time by sex) was conducted for each outcome based on student sex. To assess the effects by class grade, analysis to assess within class grade effects (introducing a 3-way interaction group by time by class grade) was conducted for each outcome based on student class grade. For the teacher-level outcomes, between-group differences in mean minutes of PA delivered across the school week at followup were assessed. These linear mixed models included fixed effects for group and the lunchbox intervention as well as a random intercept for school.

\section{Results}

Of the 26 schools randomly selected, 6 were ineligible; 20 were approached and 12 agreed to participate. Parental consent was obtained for 2148 of the $3772 \mathrm{~K}-6$ students from the 12 schools $(57.0 \%)$. At baseline, 1,948 students $(90.7 \%$ of consenting students) wore an accelerometer, 1862 of whom provided valid accelerometer data. Of these, at follow-up, 1677 students wore an accelerometer, and $1502(89.6 \%)$ of these students provided valid accelerometer data. Overall, 1502 students provided both baseline and follow-up data (Figure 1). There were no significant differences in age, sex, or socioeconomic status between consenting and nonconsenting students. Baseline characteristics of the 1862 students who wore an accelerometer and met wear time criteria are outlined in Table 2.

\section{Primary Outcome: Student's Mean Daily Activity cpm}

Table 3 shows that the average change from baseline to follow-up in whole-school day PA was statistically significantly higher in the intervention group relative to control $(97.5 \mathrm{cpm}$; $95 \%$ confidence interval $[\mathrm{CI}], 64.5-130.4 ; P<.001)$, which was also significant during class time, that is, whole school day minus recess and lunch time $(69.0 \mathrm{cpm}$; $95 \% \mathrm{CI}, 35.1-102.9, P=.001)$. The findings of the sensitivity analysis with imputed data of the primary outcome were consistent with those of the primary analysis (Table 3). Subgroup analysis for intervention effects by student sex and grade found positive effects for both girls (adjusted difference $=74.2 \mathrm{cpm} ; 95 \%$ CI, 28.7-119.6, $P=.005$ ) and boys (adjusted difference $=126.3 \mathrm{cpm}$; $95 \%$ CI, 80.1-172.5, $P<.001$ ) (Table 3 ) and variable effects by grade (Table 4). 
Table 2 Baseline Characteristics of Consenting Students Who Met Accelerometer Wear Time Criteria

\begin{tabular}{lcc}
\hline & Intervention & Comparison \\
\hline Student characteristics & & \\
Total students & $\mathrm{N}=1,169$ & $\mathrm{~N}=693$ \\
Age, mean (SD) & $(\mathrm{n}=1003)^{\mathrm{a}}$ & $(\mathrm{n}=613)^{\mathrm{a}}$ \\
& $7.96(2.03)$ & $8.05(2.05)$ \\
Sex, n (\%) female & $(\mathrm{n}=1147)^{\mathrm{a}}$ & $(\mathrm{n}=691)^{\mathrm{a}}$ \\
& $549(47.86 \%)$ & $360(52.10 \%)$ \\
Rurality, n (\%) & & \\
Rural & $23(1.97 \%)$ & $321(46.32 \%)$ \\
Urban & $1146(98.03 \%)$ & $372(53.68 \%)$ \\
SES, $\mathrm{n}(\%)$ & & \\
Most disadvantaged & $755(64.59 \%)$ & $528(76.19 \%)$ \\
Least disadvantaged & $414(35.41 \%)$ & $165(23.81 \%)$ \\
Teacher characteristics & & \\
Total teachers & $\mathrm{N}=57$ & $\mathrm{~N}=50$ \\
Age, mean (SD) & $(\mathrm{n}=52)^{\mathrm{a}}$ & $(\mathrm{n}=47)^{\mathrm{a}}$ \\
& $41.15(12.62)$ & $43.36(12.47)$ \\
Sex, n (\%) female & $(\mathrm{n}=53)^{\mathrm{a}}$ & $(\mathrm{n}=47)^{\mathrm{a}}$ \\
Years teaching experience, & $45(84.91 \%)$ & $39(82.98 \%)$ \\
mean (SD) & $(\mathrm{n}=52)^{\mathrm{a}}$ & $(\mathrm{n}=47)^{\mathrm{a}}$ \\
Class level taught & $16.18(11.49)$ & $18.05(12.90)$ \\
Lower elementary & $(\mathrm{n}=49)^{\mathrm{a}}$ & $(\mathrm{n}=48)^{\mathrm{a}}$ \\
Upper elementary & $23(46.94 \%)$ & $22(45.83 \%)$ \\
Specialist PE teacher & $26(53.06 \%)$ & $26(54.17 \%)$ \\
& $(\mathrm{n}=52)^{\mathrm{a}}$ & $(\mathrm{n}=48)^{\mathrm{a}}$ \\
\hline Abbrian & $2(3.85 \%)$ & $2(4.17 \%)$ \\
\hline
\end{tabular}

Abbreviation: PE, physical education; SES, socioeconomic status.

${ }^{\mathrm{a}}$ Data are missing due to incomplete information provided by the respondent on consent forms or surveys.

\section{Secondary Outcome: Student Mean Daily Minutes of MVPA and Sedentary Time}

Compared with controls, students in the intervention group had a significantly greater increase from baseline to follow-up in the average minutes of MVPA performed across the whole school day (adjusted difference $=3.0 \mathrm{~min} ; 95 \% \mathrm{CI}, 2.2-3.8, P<.001$ ) and during class time (adjusted difference $=3.27 \mathrm{~min} ; 95 \%$ CI, $2.65-$ $3.88, P<.001)$. The average increase in MVPA per whole school day was statistically significantly greater in both intervention girls (adjusted difference $=2.20 ; 95 \%$ CI $, 1.11-3.28, P=.001)$ and boys $($ adjusted difference $=3.97 ; 95 \%$ CI $, 2.67-5.07, P=.001)($ Table 3$)$, relative to controls. Significant MVPA effects favoring intervention students were also evident in all grade levels, with the exception of those in grades 1 and 2 (Table 4).

Compared with controls, students in the intervention group had a statistically significantly greater decline from baseline to follow-up in average sedentary time across the whole school day (adjusted difference $-2.13 \mathrm{~min} ; 95 \% \mathrm{CI},-3.86$ to $-0.40, P=.02$ ) but not during class time (adjusted difference $0.04 \mathrm{~min} ; 95 \% \mathrm{CI}$, -1.59 to $1.67, P=.96$ ). Compared with the control group, girls attending an intervention school had a statistically significantly greater decline from baseline to follow-up in average sedentary time across the whole school day (adjusted difference $-2.88 \mathrm{~min}$; $95 \% \mathrm{CI},-5.26$ to $-0.49, P=.02$ ), whereas boys did not (adjusted difference $-1.67 ; 95 \% \mathrm{CI},-4.10$ to $0.75, P=.16$ ). Children in grades 3 to 6 from the intervention group showed a statistically significantly greater decline in their average sedentary time across the whole school day from baseline to follow-up compared with controls (Table 4).

\section{Secondary Outcome: Teachers' Implementation of the PA Policy}

Table 5 shows that at follow-up, intervention teachers scheduled on average 36.60 (95\% CI, 2.68-70.51, $P=.04$ ) more minutes of PA across the school week than comparison teachers. Intervention teachers also scheduled significantly more minutes of energizers across the school week at follow-up (adjusted difference $=23.43 \mathrm{~min} ; 95 \% \mathrm{CI}, 3.24-43.62, P=.03$ ) than control teachers.

\section{Discussion}

To our knowledge, this is the first cluster RCT assessing the impact that a multicomponent intervention aimed at increasing elementary school teachers' implementation of a PA policy has on students' activity levels. Although the study was intended as a pilot, encouragingly, the trial found significant improvements in both student daily PA and teachers' implementation of the PA policy. The findings are consistent with previous investigations, which reported significant and positive associations between school time scheduled for PA and student PA levels. ${ }^{32}$ These findings support the efficacy of policies adopted by some jurisdictions internationally that set minimum periods of time that schools are required to implement as structured PA for children.

\section{Improvement in Student Activity Differed by Grade}

Although overall improvements in student daily PA, that is, cpm (97.5) and MVPA (3 min), were modest, subgroup analysis found that effect sizes significantly increased with students' age, with those in the oldest age group (grade 6) having the greatest improvement (a change of 6 min more MVPA and 15 min less sedentary activity per day from baseline to follow-up). Given that PA significantly decreases as students age, teachers' scheduling of PA may represent a simple and potentially effective strategy in achieving population-level improvements in older children's activity, in particular. Similarly, intervention effects were not uniform for both boys and girls, with measures of change in whole school day cpm and MVPA for boys approximately 1.5 times that of girls. As girls are less likely than boys to participate in PA and, in particular, MVPA, ${ }^{33,34}$ these findings suggest that teachers need to consider activities that may be particularly appealing to girls when scheduling PA. Encouraging teachers to use strategies that have been shown to engage girls in class activities, such as giving girls a "voice and choice" in the selection of activities or offering girls-only activities, may also be useful. ${ }^{35}$

\section{Significant Improvement in Teachers' Implementation of the PA Policy}

Encouragingly, this trial demonstrated the effectiveness of a package of support strategies in improving teachers' implementation of the PA policy and, in doing so, contributed to a limited 
Table 3 Changes in Physical Activity From Baseline to Follow-Up (CPM, MVPA, and Sedentary Time)

\begin{tabular}{|c|c|c|c|c|c|c|c|c|}
\hline \multirow[b]{2}{*}{ Outcome } & \multicolumn{2}{|c|}{ Intervention } & \multicolumn{2}{|c|}{ Comparison } & \multicolumn{2}{|c|}{$\begin{array}{c}\text { Available case } \\
\text { time } \times \text { group } \\
\text { interaction }\end{array}$} & \multicolumn{2}{|c|}{$\begin{array}{c}\text { Imputed data } \\
\text { time } \times \text { group } \\
\text { interaction }\end{array}$} \\
\hline & $\begin{array}{l}\text { Baseline } \\
\text { mean (SD) }\end{array}$ & $\begin{array}{l}\text { Follow-up } \\
\text { mean (SD) }\end{array}$ & $\begin{array}{l}\text { Baseline } \\
\text { mean (SD) }\end{array}$ & $\begin{array}{l}\text { Follow-up } \\
\text { mean (SD) }\end{array}$ & Mean (Cl) & $\begin{array}{c}P \\
\text { value }\end{array}$ & Mean (Cl) & $\begin{array}{c}P \\
\text { value }\end{array}$ \\
\hline $\begin{array}{l}\text { Total day } \\
\text { cpm }\end{array}$ & $\begin{array}{l}2500.92 \\
(556.61)\end{array}$ & $\begin{array}{l}2618.71 \\
(582.82)\end{array}$ & $\begin{array}{l}2556.85 \\
(557.27)\end{array}$ & $\begin{array}{l}2569.73 \\
(599.13)\end{array}$ & $\begin{array}{c}97.46 \\
(64.53 \text { to } \\
130.39)\end{array}$ & $<.01$ & $\begin{array}{c}94.92 \\
(66.66 \text { to } \\
123.18)\end{array}$ & $<.01$ \\
\hline Females & $\begin{array}{l}2353.46 \\
(507.98)\end{array}$ & $\begin{array}{l}2454.24 \\
(542.29)\end{array}$ & $\begin{array}{l}2419.45 \\
(508.66)\end{array}$ & $\begin{array}{l}2424.39 \\
(549.65)\end{array}$ & $\begin{array}{c}74.16 \\
(28.74 \text { to } \\
119.58)\end{array}$ & .01 & $\begin{array}{c}78.94 \\
(39.55 \text { to } \\
118.32)\end{array}$ & $<.01$ \\
\hline Males & $\begin{array}{l}2627.32 \\
(560.10)\end{array}$ & $\begin{array}{l}2773.09 \\
(579.17)\end{array}$ & $\begin{array}{l}2704.64 \\
(568.95)\end{array}$ & $\begin{array}{l}2727.88 \\
(611.31)\end{array}$ & $\begin{array}{c}126.27 \\
(80.06 \text { to } \\
172.49)\end{array}$ & $<.01$ & $\begin{array}{c}122.20 \\
(81.89 \text { to } \\
162.50)\end{array}$ & $<.01$ \\
\hline $\begin{array}{l}\text { Class time } \\
\mathrm{cpm}\end{array}$ & $\begin{array}{l}2031.42 \\
(494.63)\end{array}$ & $\begin{array}{l}2113.96 \\
(540.01)\end{array}$ & $\begin{array}{l}2097.73 \\
(502.82)\end{array}$ & $\begin{array}{l}2116.51 \\
(680.41)\end{array}$ & $\begin{array}{c}69.02 \\
(35.14 \text { to } \\
102.90)\end{array}$ & $<.01$ & $\begin{array}{c}81.64 \\
(52.43 \text { to } \\
110.85)\end{array}$ & $<.01$ \\
\hline $\begin{array}{l}\text { Total day } \\
\text { MVPA }\end{array}$ & $\begin{array}{c}33.74 \\
(12.37)\end{array}$ & $\begin{array}{c}37.47 \\
(14.12)\end{array}$ & $\begin{array}{c}35.88 \\
(12.51)\end{array}$ & $\begin{array}{l}35.96 \\
(12.99)\end{array}$ & $\begin{array}{c}3.02 \\
(2.23 \text { to } 3.81)\end{array}$ & $<.01$ & $\begin{array}{c}2.86 \\
(2.20 \text { to } 3.52)\end{array}$ & $<.01$ \\
\hline Females & $\begin{array}{c}30.90 \\
(12.64)\end{array}$ & $\begin{array}{c}34.28 \\
(13.47)\end{array}$ & $\begin{array}{c}33.19 \\
(11.31)\end{array}$ & $\begin{array}{c}33.38 \\
(12.36)\end{array}$ & $\begin{array}{c}2.20 \\
(1.11 \text { to } 3.28)\end{array}$ & $<.01$ & $\begin{array}{c}2.35 \\
(1.43 \text { to } 3.28)\end{array}$ & $<.01$ \\
\hline Males & $\begin{array}{c}36.21 \\
(12.64)\end{array}$ & $\begin{array}{c}40.50 \\
(14.15)\end{array}$ & $\begin{array}{c}38.77 \\
(13.07)\end{array}$ & $\begin{array}{c}38.77 \\
(13.07)\end{array}$ & $\begin{array}{c}3.97 \\
(2.86 \text { to } 5.07)\end{array}$ & $<.01$ & $\begin{array}{c}3.61 \\
(2.66 \text { to } 4.56)\end{array}$ & $<.01$ \\
\hline $\begin{array}{l}\text { Class time } \\
\text { MVPA }\end{array}$ & $\begin{array}{l}18.03 \\
(7.92)\end{array}$ & $\begin{array}{c}20.61 \\
(10.05)\end{array}$ & $\begin{array}{l}19.71 \\
(8.61)\end{array}$ & $\begin{array}{c}18.74 \\
(10.74)\end{array}$ & $\begin{array}{c}3.27 \\
(2.65 \text { to } 3.88)\end{array}$ & $<.001$ & $\begin{array}{c}3.31 \\
(2.79 \text { to } 3.83)\end{array}$ & $<.01$ \\
\hline $\begin{array}{l}\text { Total day } \\
\text { sedentary time }\end{array}$ & $\begin{array}{l}201.11 \\
(30.63)\end{array}$ & $\begin{array}{l}198.86 \\
(29.05)\end{array}$ & $\begin{array}{l}199.77 \\
(28.39)\end{array}$ & $\begin{array}{l}198.75 \\
(33.41)\end{array}$ & $\begin{array}{c}-2.13 \\
(-3.86 \text { to }-0.40)\end{array}$ & .02 & $\begin{array}{c}-2.82 \\
(-4.31 \text { to }-1.32)\end{array}$ & $<.01$ \\
\hline Females & $\begin{array}{l}206.42 \\
(30.07)\end{array}$ & $\begin{array}{l}203.27 \\
(29.07)\end{array}$ & $\begin{array}{l}204.18 \\
(27.63)\end{array}$ & $\begin{array}{l}203.61 \\
(32.60)\end{array}$ & $\begin{array}{c}-2.88 \\
(-5.26 \text { to }-0.49)\end{array}$ & .02 & $\begin{array}{c}-3.59 \\
(-5.68 \text { to }-1.50)\end{array}$ & $<.01$ \\
\hline Males & $\begin{array}{l}196.80 \\
(30.03)\end{array}$ & $\begin{array}{l}194.82 \\
(28.46)\end{array}$ & $\begin{array}{l}195.02 \\
(28.34)\end{array}$ & $\begin{array}{l}193.39 \\
(33.54)\end{array}$ & $\begin{array}{c}-1.67 \\
(-4.10 \text { to } 0.75)\end{array}$ & .16 & $\begin{array}{c}-2.51 \\
(-4.65 \text { to }-0.38)\end{array}$ & .02 \\
\hline $\begin{array}{l}\text { Class time } \\
\text { sedentary time }\end{array}$ & $\begin{array}{l}171.23 \\
(25.68)\end{array}$ & $\begin{array}{l}170.95 \\
(25.17)\end{array}$ & $\begin{array}{l}169.26 \\
(24.57)\end{array}$ & $\begin{array}{l}167.71 \\
(32.28)\end{array}$ & $\begin{array}{c}0.04 \\
(-1.59 \text { to } 1.67)\end{array}$ & .96 & $\begin{array}{c}-0.83 \\
(-2.22 \text { to } 0.56)\end{array}$ & .24 \\
\hline
\end{tabular}

Abbreviations: CI, confidence interval; cpm, counts per minute; MVPA, moderate to vigorous physical activity. Note: Boldface indicates statistical significance $(P<.05)$.

implementation evidence base for the setting. ${ }^{4}$ Specifically, teachers of intervention schools, relative to control, implemented 36 minutes more PA per week. However, these large improvements seem only to lead to modest improvements in student MVPA. Such findings suggest that the composition of activities that teachers can use to implement the 150 minutes of PA, that is, PE, sport, energizers, and integrated lessons, may impact differently on student PA. Therefore, implementation strategies that enhance the quality of teachers' implementation of PA so that it increases student MVPA during these activities may be required to further enhance student activity levels.

A lack of time and concerns regarding encroachment of PA into other key learning areas is frequently cited as a barrier to the implementation of school-based PA interventions. ${ }^{13}$ Enhancements in teachers' implementation of the PA policy, however, were achieved without significantly impacting on time allocated to other learning areas. Given the significant increase in teachers' implementation of energizers (23.43 min), the findings suggest that such strategies may have been effective in improving time for PA without compromising time allocation for other learning objectives. There is significant evidence to suggest that the use of energizers could enhance student cognitive function ${ }^{14}$ as well as their PA. As such, greater targeting of time scheduled for specific activities, such as energizers, may yield greater improvements in student MVPA given their engagement of whole classes in short bouts of MVPA. Research to identify the type of scheduled activities associated with the greatest activity gains is, therefore, warranted. Nonetheless, the trial provides policy makers with a strategy capable of achieving implementation of an intervention with sufficient fidelity to achieve improvements in child PA that could be considered for broader application.

\section{Limitations}

The findings of the study should be considered in the context of a number of limitations. First, the trial was conceptualized as a pilot and assessed outcomes immediately post intervention. A larger RCT with a greater number of clusters is required to verify the findings of this trial and to assess the longer term sustainability of reported improvements on PA. Second, the trial assessed PA across the school day. Potentially, increases in PA occurring at school may have been offset by some reductions occurring outside of school hours. As 24-hour PA data were not assessed, the extent to which this occurred is unknown. Third, to assess policy implementation, teachers were asked to complete a logbook for 1 week during followup only. Although it appears that the stratified randomization 
Table 4 Changes in Physical Activity From Baseline to Follow-Up (CPM, MVPA, and Sedentary Time) by Class Grade

\begin{tabular}{|c|c|c|c|c|c|c|}
\hline \multirow[b]{2}{*}{ Outcome } & \multicolumn{2}{|c|}{ Intervention } & \multicolumn{2}{|c|}{ Comparison } & \multicolumn{2}{|c|}{$\begin{array}{c}\text { Available case } \\
\text { time } \times \text { group interaction }\end{array}$} \\
\hline & $\begin{array}{c}\text { Baseline } \\
\text { mean (SD) }\end{array}$ & $\begin{array}{l}\text { Follow-up } \\
\text { mean (SD) }\end{array}$ & $\begin{array}{c}\text { Baseline } \\
\text { mean (SD) }\end{array}$ & $\begin{array}{l}\text { Follow-up } \\
\text { mean (SD) }\end{array}$ & Mean (Cl) & $P$ value \\
\hline \multicolumn{7}{|l|}{ Total day cpm } \\
\hline Kindergarten & $2655.97(542.38)$ & $2718(512.62)$ & $2665.32(566.27)$ & $2767.16(508.97)$ & $-14.27(-101.19$ to 72.64$)$ & .72 \\
\hline Year 1 & $2628.23(525.70)$ & $2657.78(531.25)$ & $2775.65(537.12)$ & $2800.24(544.28)$ & $-34.71(-115.97$ to 46.54$)$ & .36 \\
\hline Year 2 & $2645.76(561.82)$ & $2574.88(549.79)$ & $2657.09(484.44)$ & $2656.14(536.23)$ & $-77.39(-168.64$ to 13.86$)$ & .09 \\
\hline Year 3 & $2520.06(546.86)$ & $2606.98(603.13)$ & $2582.73(492.19)$ & $2574.51(553.40)$ & $150.99(67.35$ to 234.63$)$ & $<.01$ \\
\hline Year 4 & $2418.60(498.64)$ & $2675.92(586.58)$ & $2586.95(589.90)$ & $2513.77(603.84)$ & 269.66 (183.72 to 355.60$)$ & $<.01$ \\
\hline Year 5 & $2330.52(542.26)$ & $2515.02(638.69)$ & $2357.31(481.26)$ & $2378.66(564.03)$ & $211.82(126.37$ to 296.93$)$ & $<.01$ \\
\hline Year 6 & $2204.28(512.59)$ & $2523.74(669.95)$ & $2312.57(575.62)$ & $2334.60(696.70)$ & 290.38 (182.33 to 398.43$)$ & $<.01$ \\
\hline \multicolumn{7}{|l|}{ Total day MVPA } \\
\hline Kindergarten & $35.15(11.23)$ & $39.71(13.04)$ & $39.21(12.58)$ & $39.67(11.53)$ & $3.37(1.32$ to 5.41$)$ & .01 \\
\hline Year 1 & $36.18(12.18)$ & $38.00(12.76)$ & 38.79 (12.39) & $41.38(12.16)$ & $-0.51(-2.48$ to 1.47$)$ & .58 \\
\hline Year 2 & $35.70(12.17)$ & 36.05 (13.30) & $35.72(10.88)$ & $37.47(12.85)$ & $-1.03(-3.19$ to 1.14$)$ & .31 \\
\hline Year 3 & $34.63(12.88)$ & $37.68(14.16)$ & $36.67(11.71)$ & $35.99(12.11)$ & 4.55 (2.59 to 6.50$)$ & $<.01$ \\
\hline Year 4 & $32.27(11.60)$ & $37.51(13.64)$ & $34.95(13.24)$ & $33.82(12.80)$ & 4.53 (2.49 to 6.56$)$ & $<.01$ \\
\hline Year 5 & $29.71(11.25)$ & $36.33(16.33)$ & $31.87(10.28)$ & $32.90(12.16)$ & 5.10 (2.96 to 7.24$)$ & $<.01$ \\
\hline Year 6 & $29.77(11.93)$ & $35.94(16.22)$ & $32.08(12.58)$ & $31.22(14.00)$ & $6.02(3.44$ to 8.60$)$ & $<.01$ \\
\hline \multicolumn{7}{|c|}{ Class time MVPA } \\
\hline Kindergarten & $19.87(7.46)$ & $23.35(9.02)$ & $21.53(9.34)$ & $19.71(9.72)$ & $4.93(3.44$ to 6.41$)$ & $<.01$ \\
\hline Year 1 & $19.95(8.00)$ & $19.73(7.33)$ & $20.43(8.18)$ & $22.65(11.50)$ & $-2.06(-3.50$ to -0.61$)$ & .01 \\
\hline Year 2 & $18.73(8.00)$ & $19.44(8.17)$ & $20.25(7.84)$ & $19.37(8.91)$ & $1.92(0.44$ to 3.41$)$ & .02 \\
\hline Year 3 & $18.05(7.98)$ & $19.72(8.72)$ & $20.55(8.51)$ & $16.92(10.14)$ & 6.38 (4.94 to 7.82$)$ & $<.01$ \\
\hline Year 4 & $16.56(6.58)$ & $20.93(10.55)$ & $18.44(8.06)$ & $17.66(10.27)$ & 4.48 (2.79 to 6.16$)$ & $<.01$ \\
\hline Year 5 & $15.50(7.03)$ & $20.70(13.82)$ & $17.26(7.17)$ & $16.73(10.10)$ & 5.28 (3.43 to 7.14$)$ & $<.01$ \\
\hline Year 6 & $14.96(6.67)$ & $20.31(12.38)$ & $16.88(8.68)$ & $18.58(12.81)$ & $3.43(1.21$ to 5.64$)$ & $<.01$ \\
\hline \multicolumn{7}{|c|}{ Total day sedentary time } \\
\hline Kindergarten & $190.60(28.44)$ & $194.34(24.28)$ & $195.94(26.46)$ & $188.53(30.28)$ & $11.57(7.04$ to 16.11$)$ & $<.01$ \\
\hline Year 1 & $194.89(27.75)$ & $197.58(27.40)$ & $191.11(22.40)$ & $193.05(28.73)$ & $-0.80(-4.81$ to 3.22$)$ & .66 \\
\hline Year 2 & $164.99(30.05)$ & $200.16(28.26)$ & $193.25(23.85)$ & $193.78(29.26)$ & $3.31(-1.08$ to 7.70$)$ & .12 \\
\hline Year 3 & $201.01(29.05)$ & $200.20(31.20)$ & $198.21(26.28)$ & $200.17(30.12)$ & $-7.02(-11.64$ to -2.40$)$ & $<.01$ \\
\hline Year 4 & $205.16(30.09)$ & $193.88(29.09)$ & $200.38(28.62)$ & $196.38(34.03)$ & $-8.00(-12.73$ to -3.26$)$ & $<.01$ \\
\hline Year 5 & $213.93(28.12)$ & $204.13(31.44)$ & $209.38(28.64)$ & $208.39(33.45)$ & $-7.78(-12.33$ to -3.24$)$ & $<.01$ \\
\hline Year 6 & $222.93(29.29)$ & $205.09(29.70)$ & $214.73(31.90)$ & $209.05(40.90)$ & $-15.57(-21.16$ to -9.98$)$ & $<.01$ \\
\hline
\end{tabular}

Abbreviations: $\mathrm{CI}$, confidence interval; cpm, counts per minute; MVPA, moderate to vigorous physical activity. Note: Boldface indicates statistical significance $(P<.05)$.

Table 5 Classroom Teachers' Minutes of PA Implemented Across the School Week at Follow-Up

\begin{tabular}{|c|c|c|c|c|}
\hline \multirow[b]{2}{*}{ Minutes of PA implemented } & \multicolumn{2}{|c|}{ Follow-up, mean (SD) } & \multicolumn{2}{|c|}{ Adjusted difference at follow-up } \\
\hline & $\begin{array}{l}\text { Intervention } \\
(\mathrm{N}=57)\end{array}$ & $\begin{array}{c}\text { Comparison } \\
(N=50)\end{array}$ & Estimate (Cl) & $P$ value (adjusted) \\
\hline Total PA minutes across whole day & $135.95(59.46)$ & $99.04(51.83)$ & $36.60(2.68$ to 70.51$)$ & .04 \\
\hline $\mathrm{PE}$ & $32.93(35.05)$ & $25.00(30.25)$ & $10.32(-9.88$ to 30.52$)$ & .27 \\
\hline Energizers & $45.17(31.02)$ & $19.10(25.31)$ & 23.43 (3.24 to 43.62$)$ & .03 \\
\hline Sport & $40.79(25.53)$ & $45.10(24.04)$ & $-4.13(-19.57$ to 11.31$)$ & .55 \\
\hline Integrated lessons & $23.72(30.37)$ & $13.30(38.73)$ & $10.21(-5.64$ to 26.06$)$ & .20 \\
\hline All other key learning areas & $1025.33(350.78)$ & $1061.95(320.30)$ & $-18.65(-216.27$ to 178.98$)$ & .83 \\
\hline
\end{tabular}

Abbreviations: CI, confidence interval; PA, physical activity; PE, physical education. Note: Boldface indicates statistical significance $(P<.05)$. 
achieved baseline equivalence for most school and student-level characteristics, it is possible that there were differences between groups on measures of baseline policy implementation. If this was the case, the observed effect at follow-up on this measure may have been smaller or larger than reported. Furthermore, it is possible that the process of undertaking completing logbooks may have modified usual undertaking of planned physical activities by class teachers-a form of research activity. If that was the case, the level of program implementation reported is likely to be an overestimate. However, as both intervention and control teachers were asked to complete the teacher logbook, this overestimation should be experienced by both experimental groups. Finally, as the implementation intervention was multistrategy, it is unknown the relative contribution that each specific strategy had on improving teachers' policy implementation or on measures of child PA.

\section{Conclusions}

The findings of this study suggest that increasing time scheduled for structured PA may be an acceptable and effective strategy to improve student activity and offers an evidence-based strategy for policy makers and practitioners to achieve implementation. Although the trial provides valuable information for policy makers and practitioners, future research is required to verify the long-term impacts of the intervention and the capacity of the intervention to be delivered and retain effects at scale. ${ }^{36}$

\section{Acknowledgments}

The work was supported by Hunter Medical Research Institute (HMRI), Hunter Children's Research Foundation (HCRF), and Hunter New England Population Health. The authors wish to thank the participants for their involvement in this study. N.K.N. is supported by an NHMRC TRIP Fellowship (APP1132450) and a Hunter New England Clinical Research Fellowship; L.W. is supported by an NHMRC Career Development Fellowship (APP1128348), Heart Foundation Future Leader Fellowship (101175), and a Hunter New England Clinical Research Fellowship; R.L.S. is supported by an NHMRC TRIP Fellowship (APP1150661). None of the funding bodies had a role in the design, data collection, analysis, interpretation of data, and dissemination of findings. All authors declare that they have no financial disclosures. Trial Registration: Australian New Zealand Clinical Trials Registry ACTRN12616001228471.

\section{References}

1. Okely AD, Salmon J, Vella SA, et al. A Systematic Review to inform the Australian Sedentary Behaviour Guidelines for Children and Young People. Australian Government Department of Health; 2012.

2. World Health Organisation. Global strategy on diet, physical activity and health. World Health Organization; 2004. http://www.who. int/dietphysicalactivity/goals/en/index.html. Accessed December 8, 2013.

3. Tremblay MS, Gray CE, Akinroye K, et al. Physical activity of children: a global matrix of grades comparing 15 countries. J Phys Act Health. 2014;11(suppl):S113-S125. doi:10.1123/jpah.2014-0177

4. Wolfenden L, Nathan NK, Sutherland R, et al. Strategies for enhancing the implementation of school-based policies or practices targeting risk factors for chronic disease. Cochrane Database Syst Rev. 2017; 11(11):CD011677.

5. Barr-Anderson DJ, AuYoung M, Whitt-Glover MC, Glenn BA, Yancey AK. Integration of short bouts of physical activity into organizational routine a systematic review of the literature. Am J Prev Med. 2011;40(1):76-93. PubMed ID: 21146772 doi:10.1016/j. amepre.2010.09.033

6. Strong WB, Malina RM, Blimkie CJ, et al. Evidence based physical activity for school-age youth. J Pediatr. 2005;146(6):732-737. PubMed ID: 15973308 doi:10.1016/j.jpeds.2005.01.055

7. NSW Government. Rationale for Change; Sport and Physical Activity Policy-Revised 2015. NSW Government: NSW Department of Education and Communities, School Sport Unit; 2015.

8. Masse LC, Naiman D, Naylor PJ. From policy to practice: implementation of physical activity and food policies in schools. Int $J$ Behav Nutr Phys Act. 2013;10:71. PubMed ID: 23731803

9. Hardman K. Physical education in schools: a global perspective. Kinesiology 2008;40(1):5-28.

10. Harrington DM, Belton S, Coppinger T, et al. Results from Ireland's 2014 report card on physical activity in children and youth. J Phys Act Health. 2014;11(suppl):S63-S68. doi:10.1123/jpah.2014-0166

11. Thompson HR, Linchey J, Madsen KA. Are physical education policies working? A snapshot from San Francisco, 2011. Prev Chronic Dis. 2013;10:E142. PubMed ID: 23968585 doi:10.5888/pcd10.130108

12. Allison K, Vu-Nguyen K, $\mathrm{Ng} \mathrm{B}$, et al. Evaluation of Daily Physical Activity (DPA) policy implementation in Ontario: surveys of elementary school administrators and teachers. BMC Public Health. 2016;16(1):746. PubMed ID: 27502505 doi:10.1186/s12889-0163423-0

13. Nathan N, Elton B, Babic M, et al. Barriers and facilitators to the implementation of physical activity policies in schools: a systematic review. Prev Med. 2018;107:45-53. PubMed ID: 29155228 doi:10. 1016/j.ypmed.2017.11.012

14. Donnelly JE, Lambourne K. Classroom-based physical activity, cognition, and academic achievement. Prev Med. 2011;52:S36S42. PubMed ID: 21281666 doi:10.1016/j.ypmed.2011.01.021

15. Watson A, Timperio A, Brown H, Best K, Hesketh KD. Effect of classroom-based physical activity interventions on academic and physical activity outcomes: a systematic review and meta-analysis. Int J Behav Nutr Phys Act. 2017;14(1):114. PubMed ID: 28841890 doi:10.1186/s12966-017-0569-9

16. McKenzie TL, Sallis JF, Faucette N, Roby JJ, Kolody B. Effects of a curriculum and inservice program on the quantity and quality of elementary physical education classes. Research Quarterly for Exercise and Sport. 1993;64(2):178-187. PubMed ID: 8341841 doi:10. 1080/02701367.1993.10608795

17. Riley N, Lubans DR, Holmes K, Morgan PJ. Findings from the EASY minds cluster randomized controlled trial: evaluation of a physical activity integration program for mathematics in primary schools. J Phys Act Health. 2016;13(2):198-206. PubMed ID: 26107532 doi: 10.1123/jpah.2015-0046

18. Sutherland R, Nathan N, Brown A, et al. A randomized controlled trial to assess the potential efficacy, feasibility and acceptability of an m-health intervention targeting parents of school aged children to improve the nutritional quality of foods packed in the lunchbox 'SWAP IT'. Int J Behav Nutr Phys Act. 2019;16(1):54. PubMed ID: 31266506 doi:10.1186/s12966-019-0812-7

19. Cane J, O'Connor D, Michie S. Validation of the theoretical domains framework for use in behaviour change and implementation research. Implement Sci. 2012;7(1):37. PubMed ID: 22530986 doi:10.1186/ 1748-5908-7-37

20. Nathan N, Wolfenden L, Bell AC, et al. Effectiveness of a multistrategy intervention in increasing the implementation of vegetable and fruit breaks by Australian primary schools: a non-randomised controlled trial. BMC Public Health. 2012;12(1):651. PubMed ID: 22889085 doi:10.1186/1471-2458-12-651 
21. Sutherland RL, Campbell EM, Lubans DR, et al. The physical activity 4 everyone cluster randomized trial: 2-year outcomes of a school physical activity intervention among adolescents. Am J Prev Med. 2016;51(2):195-205. PubMed ID: 27103495 doi:10.1016/j.amepre. 2016.02.020

22. Jones J, Wyse R, Finch M, et al. Effectiveness of an intervention to facilitate the implementation of healthy eating and physical activity policies and practices in childcare services: a randomised controlled trial. Implement Sci. 2015;10(1):147. PubMed ID: 26498746 doi:10. 1186/s13012-015-0340-Z

23. Powell BJ, Waltz TJ, Chinman MJ, et al. A refined compilation of implementation strategies: results from the Expert Recommendations for Implementing Change (ERIC) project. Implement Sci. 2015; 10(1):21. doi:10.1186/s13012-015-0209-1

24. NSW Government. Live life well @ school. 2013. http://www. healthykids.nsw.gov.au/campaigns-programs/live-life-well-@-school. aspx. Accessed December 8, 2013.

25. Chandler JL, Brazendale K, Beets MW, Mealing BA. Classification of physical activity intensities using a wrist-worn accelerometer in 812-year-old children. Pediatr Obes. 2016;11(2):120-127. PubMed ID: 25893950 doi:10.1111/ijpo.12033

26. Bessems KM, Van Assema P, Martens MK, Paulussen TG, Raaijmakers LG, De Vries NK. Appreciation and implementation of the Krachtvoer healthy diet promotion programme for 12- to 14- year-old students of prevocational schools. BMC Public Health. 2011;11(1): 909. PubMed ID: 22151954 doi:10.1186/1471-2458-11-909

27. van Nassau F, Singh AS, van Mechelen W, Paulussen TG, Brug J, Chinapaw MJ. Exploring facilitating factors and barriers to the nationwide dissemination of a Dutch school-based obesity prevention program "DOiT": a study protocol. BMC Public Health. 2013;13(1):1201. PubMed ID: 24355056 doi:10.1186/1471-2458-13-1201

28. Cradock AL, Barrett JL, Carter J, et al. Impact of the Boston active school day policy to promote physical activity among children.
Am J Health Promot. 2014;28(3)(suppl):S54-S64. doi:10.4278/ajhp. 130430-QUAN-204

29. Sutherland R, Lubans D, Nathan N, et al. A randomized trial of an intervention to facilitate the implementation of school-based practices known to increase students' moderate-to-vigorous physical activity. Am J Prev Med. 2017;53(6):818-828.

30. Australian Bureau of Statistics. Technical Paper: Census of Population and Housing: Socio-Economic Indexes For Australia (SEIFA). Cat. no. 2039.0.55.001. Canberra, Australia: Commonwealth of Australia; 2001.

31. White IR, Horton NJ, Carpenter J, Pocock SJ. Strategy for intention to treat analysis in randomised trials with missing outcome data. BMJ. 2011;342:d40. PubMed ID: 21300711 doi:10.1136/bmj.d40

32. Ward D. School Policies on Physical Education and Physical Activity. A Research Synthesis. Princeton, NJ: Active Living Research, a National Program of the Robert Wood Johnson Foundation; 2011.

33. Ridgers ND, Stratton G, Fairclough SJ. Physical activity levels of children during school playtime. Sports Med. 2006;36(4):359371. PubMed ID: 16573359 doi:10.2165/00007256-20063604000005

34. Nettlefold L, McKay HA, Warburton DE, McGuire KA, Bredin SS, Naylor PJ. The challenge of low physical activity during the school day: at recess, lunch and in physical education. Br J Sports Med. 2011;45(10):813-819. PubMed ID: 20215489 doi:10.1136/bjsm. 2009.068072

35. Murphy B, Dionigi RA, Litchfield C. Physical education and female participation: a case study of teachers' perspectives and strategies. Issues Educ Res. 2014;24(3):241-259.

36. McCrabb S, Lane C, Hall A, et al. Scaling-up evidence-based obesity interventions: a systematic review assessing intervention adaptations and effectiveness and quantifying the scale-up penalty. Obes Rev. 2019;20(7):964-982. PubMed ID: 30868745 doi:10. 1111/obr.12845 